\title{
14 -16 Yaş Grubu Çocuklarda Korfbol Temel Beceri Eğitimi Antrenman Programının Motor Gelişime Etkisi
}

DOI: $10.26466 /$ opus.672410

$*$

\author{
Canan Gülbin Eskiyecek* - Betül Bayazıt** - Dilruba Abdikoğlu *** \\ * Dr.Öğr.Üyesi, Mardin Artuklu Üniversitesi, Beden Eğitimi ve Spor Y.O, Mardin/Türkiye \\ E-Posta: cgulbineskiyecek@gmail.com ORCID: 0000-0001-6987-3609 \\ ** Doç.Dr, Kocaeli Üniversitesi, Spor Bilimleri Fakültesi, Kocaeli/Türkiye \\ E-Posta: bayazitbetul@gmail.com ORCID: 0000-0003-3547-2035 \\ *** Doktora Öğrencisi, Kocaeli Üniversitesi, Spor Bilimleri Fakültesi, Kocaeli/Türkiye \\ E-Posta: dilruba.g@hotmail.com \\ ORCID: $0000-0002-4863-2459$
}

Öz

Bu çalışmanın amacl, 14-16 yaş grubu kız ve erkek çocuklarda korfbol temel beceri eğitimi antrenmanlarının motor gelişime etkisini belirlemektir. Çalışma grubunu, Kocaeli Fen Lisesi'nde öğrenim gören ve random yöntemiyle seçilmiş 12'si kız ve 20'si erkek olmak üzere toplam 32 gönüllü̈ öğrenci oluşturmuştur. Öğrenciler cinsiyete bakılmaksızın denek $(n=17)$ ve kontrol $(n=15)$ grubu olmak üzere iki eş gruba ayrilmıştır. Çalışmada deney grubuna 8 hafta süreyle haftada 2 gün ve günde 60 dakika olmak üzere korfbol branşının temel motor becerilerini geliştirmeye yönelik beş temel beceriyi içeren (pas, şut, penaltı, turnike ve $V$ kat şut atışı) bir antrenman programı uygulanmıştır. Kontrol grubuna ise herhangi bir antrenman programı uygulanmamıştır. Çalışmanın yürütülebilmesi için 2019/01.2 sayılı ve 2018/346 proje (KÜ GOKAEK) ile Etik Kurul Onayı alınmıştır. Elde edilen verilere, SPSS programı ile tanımlayıcı istatistiksel işlemlerle birlikte gruplar arasındaki farkı belirlemek için Mann Whitney U testi, grupların kendi içerisindeki farkı belirlemek için ise Wilcoxon testi kullanılmıştır. Sonuçlar $p<0.05$ önemlilik düzeyinde değerlendirilmiştir. Çalışmada ön-test ve son-test ölçüm değerlerinin karşılaştırlmasında, denek grubunun pas, şut, penaltı, turnike ve $V$ kat şut atışı değişkenleri arasında istatistiksel olarak önemli düzeyde fark olduğu tespit edilmiştir ( $p<0.05$ ). Çalışma sonucunda, 8 hafta süresince pas tekniği ile birlikte şut tekniklerini geliştirmeye yönelik yapılan antrenmanlar çocukların korfbol temel motor becerileri üzerinde iyileşmeler sağlamıştır.

Anahtar Kelimeler: Korfbol, Motor Beceri, Motor Gelişim 


\title{
The Effect of Korfball Basic Skill Education Training Program on Motor Development in Children of 14 -16 Years
}

*

\begin{abstract}
The purpose of this study, the 14-16 age group boys and girls in korfball basic skills education training is designed for motor development. The study group consisted of 32 volunteer students (12 girls and 20 boys) randomly selected from Kocaeli Science High School. The students were divided into two peer groups, as the subject $(n=17)$ and the control $(n=15)$ groups regardless of gender. In the study, a training program including five basic skills was applied to the experimental group for 8 weeks, 2 days a week and 60 minutes a day for improving the basic motor skills of the korfball branch. The control group did not receive any training program. Ethics Committee Approval was obtained with 2019/01.2 and 2018/346 projects (KU GOKAEK) in order to carry out the study whose content is determined. After the descriptive statistical procedures were applied with SPSS program, Mann Whitney U test was used to determine the difference between the groups and Wilcoxon test was used to determine the difference within the groups. The results were evaluated at $p<0.05$ significance level. In the study, when the pre-test and post-test measurement values were compared, it was found that there was a statistically significant significant difference between the variables of pass, shot, penalty, turnstile and $V$-fold shot of the subject gorups $(p<0.05)$. As a result of the study, it was found out that the trainings performed for 8 weeks to improve shooting techniques together with rust technique improved the korfball basic motor skills of the children
\end{abstract}

Keywords: Korfball, Motor Skill, Motor Development 


\section{Giriş}

İnsanın gelişimi fiziksel, bilişsel, duyuşsal ve sosyal boyutların bir arada ele alınarak geliştirilmesiyle mümkün olmaktadır. Hareket, bedenin herhangi bir bölümünün gözlenebilir pozisyon değişikliği ve ayrıca temel motor süreçlerin en üst eylemi olarak açılanmaktadır (Gallahue, 2014). Hareket beceri ve tekniklerinin en hızı kazandırılabildiği dönem gelişimin en hızlı olduğu çocukluk dönemidir. Bu dönemde alınan iyi eğitim, kişinin yaşam boyu hem fiziksel hem de psikolojik açıdan sağlıklı ve zinde olmasını sağlamaktadır. Spor, çocukların fiziksel, motorsal, zihinsel ve duygusal açıdan gelişmelerine katkı sağlamaktadır (Sema, 2007; Polat, 2009). Dolayısıyla sporun, çocukların gelişimleri üzerinde bilinen faydasından kaynaklı çocukluk döneminde yapılan spor faaliyetlerinin çocukların yaşam kalitelerini olumlu yönde etkileyeceği öngörülmektedir.

Dünya çapında başarıya ulaşmanın bilimsel temellerinden biri, yetenekli gençlerin erken yaşlardan itibaren o spor alanına seçilmesidir (Biçici ve ark., 2009). Ülkemizde uluslararası yarışmalarda yetenekli sporcuların temsil ettiği spor branşlarından biri olan korfbol branşının oyuncuları fiziksel özellikleri açısından diğer sporculardan göreceli olarak daha az vücut yağına, daha fazla yağsız vücut kütlesine, daha fazla uzuv yağına ve daha az veya benzer gövde yağına sahiptir. Bununla birlikte, erkek korfbolcular dayanıklılık sporcularına benzer bir somatotip ve diğer sporculardan daha düşük veya benzer bir endomorfik yapıya sahipken, kadın korfbolcular ise somatotipi ile diğer sporcuların somatotipleri arasındaki tek belirgin benzerlik mezomorfi yapının hakim olmasidır (Godinho ve ark., 1996).

Korfbol oyunu, 1901 yilında Hollanda'nın Amsterdam kentinde karma bir ilköğretim okulu'nda Beden Eğitimi Öğretmeni olan Ni-o Broekhuysen tarafından bulunmuştur. Broekhuysen bu oyunu, 1902 yılında İsveç'te oynadığı bir oyundan esinlenerek tasarlamıştır (Korfball, 2020). 1903 yılında Hollanda Korfbol Birliği kurulurken, Uluslararası Korfbol Federasyonu (IKF) 1933 yılında kurulmuştur. Türkiye'de ise bu spor ilk olarak 1995 yılında Marmara Üniversitesi ve FMV Özel Işık Lisesi'nde başlamıştır (Güler, 1998). Korfbol sporunun gelişiminde ana katalizör, erkeklerin ve kızların bir seviye oyun alanına katılabileceği anlamına gelmesi ve işbirliğine dayanan ve karışık bir spora ihtiyaç duyulmasıdır (Summerfield ve White, 1989). 
Oyunun amacı, topu rakip takımın korf adı verilen sepetine atış yapmaktır. Bir takımın sahada 4 kadın 4 erkek olmak üzere toplam 8 oyuncusu bulunmaktadır. Rakip takımın da aynı şekilde dağılımını yapması gerekmektedir. Çok yönlülük gerektiren korfbolda bir oyuncu hem hücum hem de defans görevini en iyi şekilde yerine getiriyor olmalıdır. Çünkü takım oyuncularından 2 kadın - 2 erkek bir yarı sahada hücum yaparken, bir diğer 2 kadın - 2 erkek ise diğer yarı sahada savunma yaparlar ve her iki sayıda bir saha ve görev değiştirirler. Hücum yapan oyuncular savunmaya, savunma yapan oyuncular hücuma geçerler. Dolayısıyla her oyuncu hem hücum hem de savunma becerilerini geliştirmelidir (Güler, 1998).

Korfbol oyununda hücum süresi 25 sn olup, maç süreleri organizasyonların büyüklüğüne göre değişkenlik göstermektedir. Atılan gol sayısı iki ve ikinin katı olduğunda saha değişikliği yapılarak hücum ve savunma oyuncuları yer değiştirir. Oyun sahası $20 \mathrm{~m}$ genişliğinde ve $40 \mathrm{~m}$ uzunluğundadır. Korf'un uzunluğu 3,5 m, çapı 42 cm'dir. Topun çevresi $68 \mathrm{~cm}$, ağırlığ ise 475 gr'dir.

Fiziksel büyüme ve motor gelişim birbirine bağlıdır. Motor gelişim; kas, kemik, sinir sistemi, beyin gibi vücut organlarının büyümesi ve gelişmesiyle organizmanın hareket edebilme yeteneğidir. İnsan hareketleri refleks hareketler ve bilinçli hareketler olmak üzere 2'ye ayrılmaktadır. Motor gelişim süreci, hareket etmek için gerekli olan yeteneklerin gelişimini ve motor becerilerin kazanılmasını kapsamaktadır (Polat, 2009; Oxendine, 1982).

İnsan organizması kuvvet, dayanıklılık, sürat veya beceri gerektiren motor eylemleri gerçekleştirebilmek için motor özelliklerini kullanmaktadır. İşte bu motorik özelliklerde iyi ve etkili bir antrenman programı kullanılarak, kuvvet, koordinasyon, hız, çeviklik ve denge gibi unsurlar iyileştirilebilir (Günsel, 2004; Oxendine, 1982).

Literatür incelendiğinde çocuklarda korfbol temel becerileri ile ilgili çalışmaların kısıtlı olduğu görülmektedir. Dolayısıyla bu branşa özgü temel teknik becerilerin, motorik özelliklerin ve koordinatif yetilerin geliştirilmesine yönelik araştırmaların yapılmasına gereksinim duyulduğu düşünülmektedir. Bu bağlamda yapılan bu çalışma, korfbol branşına yönelik temel beceri antrenmanlarının 14-16 yaş grubu kız ve erkek çocukların motor gelişimleri üzerine ne gibi etkiler sağlayacağını belirlemek amacıyla yapılmıştır. 


\section{Yöntem}

\section{Araştırma Grubu}

Çalışma, Kocaeli Fen Lisesi'nde öğenim gören ve random yöntemiyle seçilmiş 12 kız ve 20 erkek olmak üzere toplam 32 gönüllü öğrencinin katılımıyla gerçekleşmiştir. Çalışmada cinsiyete bakılmaksızın, öğrenciler rastgele yöntemle 17'si (5 k1z- 12 erkek) denek ve 15'i (7 k1z- 8 erkek) kontrol grubu olmak üzere iki eş gruba ayrılmıştır. Çalışmada tüm öğrenciler ve velilerden imzalı "Bilgilendirilmiş Gönüllü Olur Formu" alınmıştır. Ayrıca öğrencilere uygulanan antrenmanlar için Kocaeli Fen Lisesi Spor Salonu'nda gerçekleştirilmiş olup okul idaresinden gerekli resmi izinler alınmıştır.

Çalışmanın yürütülebilmesi için Kocaeli Üniversitesi Girişimsel Olmayan Klinik Araştırmalar Etik Kurulu'ndan "KOGOEK 2019/01.2" sayılı ve "KÜ GOKAEK 2018/346" ile Etik Kurul Onayı alınmıştır.

\section{Veri Toplama Araçlan}

Çalışmada, deney ve kontrol grubundaki çocukların korfbol temel beceri eğitimi antrenmanlarının motor gelişime etkisini belirlemek amacıyla "Motor Davranış Değişikliğine Yönelik Gözlem Formu" ndan (pas, şut, penaltı, turnike ve $\mathrm{V}$ kat şut atışı) yararlanılmış olup, bu form antrenman programinın öncesinde ve sonrasında öğrencilere uygulanmıştır. Gözlem formları 5'li Likert tipinde oluşturulmuş ve gözlem formlarında 0-5 puan arasında yapılan puanlamaya göre, 1 puan "yapamadi", 2 puan "az yapti", 3 puan "yaptı", 4 puan "iyi yaptı", 5 puan ise "çok iyi yaptı" şeklinde puanlanmıştır.

Deney grubuna, 8 hafta süreyle haftada 2 gün ve günde $60 \mathrm{dk}$ olmak üzere korfbol temel hareket becerilerini geliştirmeye yönelik lokomotor, dengeleme ve manipülatif hareketleri içeren bir antrenman programı uygulanmıştır. İçeriği belirlenen antrenman programının yüklenme şiddeti iki haftada bir \%5 oranında artırılmıştır. Kontrol grubuna ise herhangi bir antrenman programı uygulanmamıştır (Tablo 1). 
Tablo 1. 8 Haftalik Antrenman Programı

\begin{tabular}{|c|c|c|c|c|c|c|c|c|}
\hline Günler & 1.Hafta & 2.Hafta & 3.Hafta & 4.Hafta & 5.Hafta & 6.Hafta & 7.Hafta & 8.Hafta \\
\hline \multirow{22}{*}{ 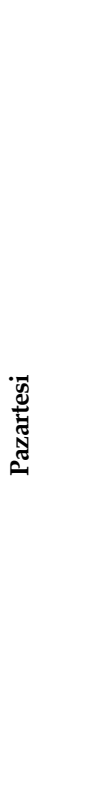 } & Isınma: & Isınma: & Isınma: & Isınma: & Isınma: & Isınma: & Isınma: & Isınma: \\
\hline & $10 \mathrm{dk}$ & $10 \mathrm{dk}$ & $10 \mathrm{dk}$ & $10 \mathrm{dk}$ & $10 \mathrm{dk}$ & $10 \mathrm{dk}$ & $10 \mathrm{dk}$ & $10 \mathrm{dk}$ \\
\hline & Esneme: & Esneme: & Esneme: & Esneme: & Esneme: & Esneme: & Esneme: & Esneme: \\
\hline & $5 \mathrm{dk}$ & $5 \mathrm{dk}$ & $5 \mathrm{dk}$ & $5 \mathrm{dk}$ & $5 \mathrm{dk}$ & $5 \mathrm{dk}$ & $5 \mathrm{dk}$ & $5 \mathrm{dk}$ \\
\hline & Şiddet: & Şiddet: & Şiddet: & Şiddet: & Şiddet: & Şiddet: & Şiddet: & Şiddet: \\
\hline & $\% 65$ & $\% 65$ & $\% 70$ & $\% 70$ & $\% 75$ & $\% 75$ & $\% 80$ & $\% 80$ \\
\hline & Kapsam: & Kapsam: & Kapsam: & Kapsam: & Kapsam: & Kapsam: & Kapsam: & Kapsam: \\
\hline & $15 \mathrm{dk}$ & $15 \mathrm{dk}$ & $15 \mathrm{dk}$ & $15 \mathrm{dk}$ & $15 \mathrm{dk}$ & $15 \mathrm{dk}$ & $15 \mathrm{dk}$ & $15 \mathrm{dk}$ \\
\hline & Tekrar & Tekrar & Tekrar & Tekrar & Tekrar & Tekrar & Tekrar & Tekrar \\
\hline & Sayısı: & Sayısı: & Sayısı: & Sayısı: & Sayısı: & Sayısı: & Sayısı: 8 & Sayısı: 8 \\
\hline & 15 & 20 & 25 & 20 & 15 & 20 & Tekrar & Tekrar \\
\hline & Tekrar & Tekrar & Tekrar & Tekrar & Tekrar & Tekrar & Arası & Arası \\
\hline & Arası & Arası & Arası & Arası & Arası & Arası & Dinlen- & Dinlen- \\
\hline & Dinlen- & Dinlen- & Dinlen- & Dinlen- & Dinlen- & Dinlen- & me: $20 \mathrm{sn}$ & me: $20 \mathrm{sn}$ \\
\hline & me: $20 \mathrm{sn}$ & me: 20 sn & me: 20 sn & me: 20 sn & me: $20 \mathrm{sn}$ & me: 20 sn & Set: 10 & Set: $\quad 5$ \\
\hline & Set: 8 & Set: 6 & Set: 6 & Set: $\quad 8$ & Set: $\quad 8$ & Set: $\quad 8$ & Setler & Setler \\
\hline & Setler & Setler & Setler & Setler & Setler & Setler & Arası & Arası \\
\hline & Arası & Arası & Arası & Arası & Arası & Arası & Dinlen- & Dinlen- \\
\hline & Dinlen- & Dinlen- & Dinlen- & Dinlen- & Dinlen- & Dinlen- & me: & me: \\
\hline & me: $2 \mathrm{dk}$ & me: & me: & me: & me: & me: & $2 \mathrm{dk}$ & $2 \mathrm{dk}$ \\
\hline & Soğuma: & $2 \mathrm{dk}$ & $2 \mathrm{dk}$ & $2 \mathrm{dk}$ & $2 \mathrm{dk}$ & $2 \mathrm{dk}$ & Soğuma: & Soğuma: \\
\hline & $10 \mathrm{dk}$ & $\begin{array}{l}\text { Soğuma: } \\
\text { 10dk }\end{array}$ & $\begin{array}{l}\text { Soğuma: } \\
\text { 10dk }\end{array}$ & $\begin{array}{l}\text { Soğuma: } \\
\text { 10dk }\end{array}$ & $\begin{array}{l}\text { Soğuma: } \\
\text { 10dk }\end{array}$ & $\begin{array}{l}\text { Soğuma: } \\
10 \mathrm{dk}\end{array}$ & $10 \mathrm{dk}$ & $10 \mathrm{dk}$ \\
\hline \multirow{13}{*}{ 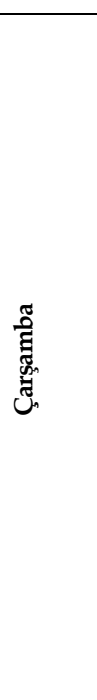 } & Hareket- & Hareket- & Hareket- & \multirow{13}{*}{$\begin{array}{l}\text { Hareket- } \\
\frac{\text { ler: }}{1-} \\
\text { Turnike } \\
\text { atış1 } \\
\text { (sağ-sol) } \\
\text { 2- V Kat } \\
\text { şut } \\
\text { 3- } \\
\text { Korf'un } \\
\text { altından } \\
\text { kısa } \\
\text { mesafe } \\
\text { atış } \\
\text { 4- } \\
\text { Penaltı } \\
\text { atış1 }\end{array}$} & Hareket- & \multirow{2}{*}{$\frac{\text { Hareket- }}{\text { ler: }}$} & Hareket- & Hareket- \\
\hline & ler: & ler: & ler: & & ler: & & ler: & ler: \\
\hline & $\begin{array}{l}\overline{1-} \\
\text { Göğüs } \\
\text { pası }\end{array}$ & $\begin{array}{l}\overline{1-} \text { Tek el } \\
\text { (sağ-sol) } \\
\text { pas }\end{array}$ & $\begin{array}{l}\overline{1-} \text { Tek el } \\
\text { pas (sağ- } \\
\text { sol) }\end{array}$ & & $\begin{array}{l}\overline{1-} \text { V Kat } \\
\text { şut } \\
2-\end{array}$ & $\begin{array}{l}\overline{1-} \text { V Kat } \\
\text { şut } \\
\text { (sağ-sol) }\end{array}$ & $\begin{array}{l}\text { 1- Tek el } \\
\text { pas (sağ- } \\
\text { sol) }\end{array}$ & $\begin{array}{l}\overline{1-} \text { Tek el } \\
\text { pas (sağ- } \\
\text { sol) }\end{array}$ \\
\hline & 2- $\quad$ Baş & $2-$ & 2-Penaltı & & Korf'un & $2-$ & $2-$ & $2-$ \\
\hline & üstü pas & Penaltı & atışı & & altından & Turnike & Penaltı & Penaltı \\
\hline & 3- Tek el & atışı & & & kisa & atışı & atışı & atışı \\
\hline & pas (sağ- & & Turnike & & mesafe & (sağ-sol) & & \\
\hline & $\begin{array}{l}\text { sol) } \\
4-\end{array}$ & $\begin{array}{l}\text { Turnike } \\
\text { atış1 }\end{array}$ & $\begin{array}{l}\text { atışı } \\
\text { (sağ-sol) }\end{array}$ & & $\begin{array}{l}\text { şut } \\
3-\end{array}$ & $\begin{array}{l}\text { 3- Şut } \\
\text { atışı }\end{array}$ & $\begin{array}{l}\text { Turnike } \\
\text { atışı }\end{array}$ & $\begin{array}{l}\text { Turnike } \\
\text { atışı }\end{array}$ \\
\hline & Bounce & (sağ-sol) & 4- Şut & & Korf'un & & (sağ-sol) & (sağ-sol) \\
\hline & pas & & atışı & & önünden & Penaltı & 4- Şut & 4- Şut \\
\hline & & & & & şut & atışı & atış1 & atışı \\
\hline & Hareket- & & & & $4-$ & & 5- V Kat & 5- V Kat \\
\hline & li pas & & & & $\begin{array}{l}\text { Korf'un } \\
\text { yanın- } \\
\text { dan kısa } \\
\text { mesafe } \\
\text { şut }\end{array}$ & & $\begin{array}{l}\text { şut (sağ - } \\
\text { sol) }\end{array}$ & $\begin{array}{l}\text { şut } \\
\text { (sağ-sol) }\end{array}$ \\
\hline
\end{tabular}


Antrenmanların genel içeriğinde pas tekniğini geliştirmek için eşli ve hareketli pas çalışmaları ile birlikte şut tekniklerini geliştirici çalışmalar yapılmıştır. Çalışmada 8 hafta süresince yapılan antrenmanlarda beş farklı korfbol hareket becerisini (pas, penaltı, turnike, şut ve V kat şut) geliştirmeye yönelik çalışmalar uygulanmıştır. Bu tekniklerin maç koşullarında uygulanması amaçlanmıştır. Antrenman programının içeriğinde; pas tekniklerini geliştirmek için ikişerli gruplar oluşturulup pas teknikleri çalıştırılmıştır. Penaltı tekniğini geliştirmek için çocuklar iki gruba ayrılarak öncelikle penaltı tekniği gösterilmiş ve penaltı atışları yaptırılmıştır. Turnike tekniğini geliştirmek için turnike adımlamaları ve topun elden çıkışı gösterilip çalıştırılmıştır. Çocukları teşvik etmek ve tekniği pekiştirmek için aralarında gruplar oluşturularak turnike yarışmaları yapılmıştır. Ardından ikili gruplar halinde birbirleriyle paslaşarak turnikeler atmışlardır. Şut tekniği için sağa ve sola doğru adımlamalar ve topun elden çıkışı gösterilip çalıştırılmıştır. Öncelikle kısa mesafe şutlar çalıştırılıp daha sonrasında zorlaştırılarak mesafe arttırılmıştır. İkili gruplar halinde birbirleriyle paslaşarak şutlar atmışlardır. V kat şut tekniğini geliştirmek için koşu adımlamaları ve topu kazanma gösterilmiştir. Pekiştirmek için çocuklara çizgide sıra olarak sürekli V kat koşular yaptırılmıştır. Daha sonrasında şut eklenerek V kat şut atmaları istenmiştir. İkili gruplar halinde birbirleriyle paslaşarak V kat şutlar atmışlardır. Antrenmanlarda teknik çalışmalar bittikten sonra tekniklerin pekiştirilmesi amacıyla 10 'ar dakika öğrenilen teknikler üzerinden iki gruba ayrılarak yarışmalar yapılmıştır.

Deney ve kontrol gruplarının, korfbol branşına yönelik beş temel becerilerinden pas teknikleri, şut tekniği, turnike tekniği, V kat sonrası şut tekniği ve penaltı teknikleri gözleme dayalı olarak değerlendirilmiştir. 8 hafta süren çalışmada ön test ve son test ölçümlerinin gözlem formu üzerinde karşılaştırılması yapılmış ve sonuçlar değerlendirilmiştir.

Çalışmada boy uzunluğu, oturma yüksekliği ve çap-çevre ölçümleri mezura ile vücut ağırlığı ise Dr Hegeli marka baskül ile ölçülmüştür. Ölçümler tamamlandıktan sonra, tüm gruplara test öncesi $15 \mathrm{dk}$ dinamik ısınma yaptırılmış daha sonra çocuklar beceri testleri için önceden hazırlanmış olan istasyonlarda uygulamaya alınmışlardır. 


\section{Verilerin İstatistiksel Analizi}

Çalışmanın değişkenlerine ait tanımlayıcı istatistikler ile birlikte tüm analizler SPSS 24.0 istatistik paket programıyla yapılmıştır. Her bir alt grupta denek sayıları 30'dan az olduğu için non-parametrik testler uygulanmıştır. Eşler arası karşılaştırmalarda Wilcoxon testi, bağımsız iki grubun karşılaştırılmasında ise Mann-Whitney U testi kullanılmıştır. Sonuçların değerlendirilmesinde önemlilik düzeyi $\alpha=0,05$ olarak alınmıştır.

\section{Bulgular}

Tablo 2. Grupların Antropometrik Ölçümlerine İlişkin Tanımlayıcı İstatistikleri

\begin{tabular}{lllllllll}
\hline Değişkenler & $\mathbf{N}$ & $\mathbf{X} \pm \mathbf{S S}$ & $\mathbf{M i n}$ & $\mathbf{M a x}$ & $\mathbf{N}$ & $\mathbf{X} \pm \mathbf{S S}$ & Min & Max \\
\hline Boy Uzunluğu $(\mathrm{cm})$ & 17 & $170,82 \pm 8,68$ & 160,0 & 189,0 & 15 & $165,33 \pm 6,21$ & 157,0 & 178,0 \\
\hline Vücut Ağırlı̆̆ı $(\mathrm{kg})$ & 17 & $63,70 \pm 15,57$ & 45,0 & 90,0 & 15 & $53,12 \pm 9,19$ & 34,0 & 72,0 \\
\hline Oturma Yüksekliği(cm) & 17 & $83,87 \pm 4,54$ & 79,0 & 94,0 & 15 & $84,18 \pm 4,16$ & 77,0 & 90,0 \\
\hline Kol Uzunluğu (cm) & 17 & $34,70 \pm 2,72$ & 31,0 & 39,5 & 15 & $33,32 \pm 2,75$ & 29,0 & 38,0 \\
\hline Ön Kol Uzunluğu (cm) & 17 & $26,50 \pm 1,98$ & 22,5 & 31,0 & 15 & $27,97 \pm 6,10$ & 24,0 & 44,5 \\
\hline El Uzunluğu (cm) & 17 & $19,73 \pm 1,47$ & 16,5 & 22,0 & 15 & $19,53 \pm 1,34$ & 18,0 & 22,0 \\
\hline Bacak Uzunluğu $(\mathrm{cm})$ & 17 & $44,97 \pm 3,25$ & 40,0 & 50,0 & 15 & $44,06 \pm 3,47$ & 37,0 & 50,0 \\
\hline Uyluk Uzunluğu $(\mathrm{cm})$ & 17 & $44,07 \pm 3,37$ & 38,0 & 51,0 & 15 & $43,29 \pm 2,24$ & 39,0 & 46,5 \\
\hline Ayak Uzunluğu $(\mathrm{cm})$ & 17 & $25,43 \pm 2,03$ & 22,0 & 29,0 & 15 & $24,15 \pm 1,63$ & 22,0 & 27,0 \\
\hline
\end{tabular}

Çalışmada 14-16 yaş grubundaki deney ve kontrol gurubunun bazı antropometrik özelliklerine ilişkin ortalama, standart sapma, minimum ve maksimum değerler gibi bazı tanımlayıı ölçütlerin istatistiksel verileri Tablo 1'de görülmektedir

Tablo 3'de görüldüğü üzere, deney grubunun ön test ve son test ölçüm değerleri arasında pas atışı, şut atışı, penaltı atışı, turnike atışı ve V-kat şut atışı değişkenlerinde istatistiksel olarak önemli düzeyde farklılıklar bulunmuştur $(p=, 001)$. Kontrol grubunun ön test ve son test ölçüm değerleri arasında ise pas atışı $(p=, 002)$ penaltı atışı $(p=, 014)$ ve $V$-kat şut atışı $(p=, 025)$ değişkenlerinde istatistiksel olarak önemli düzeyde farklılıklar bulunmuştur $(\mathrm{p}<0.05)$. 
Tablo 3. Denek ve Kontrol Grubunun Grup İçi Ön Test - Son Test Değerlerinin Wilcoxon Testi Sonuçlan

\begin{tabular}{|c|c|c|c|c|c|c|c|c|c|}
\hline \multirow[b]{2}{*}{ Değişkenler } & \multicolumn{4}{|c|}{ Deney Grubu $(\mathrm{N}=17)$} & \multicolumn{3}{|c|}{ Kontrol Grubu (N=15) } & \multirow[b]{2}{*}{$\mathbf{Z}$} & \multirow[b]{2}{*}{$\mathbf{P}$} \\
\hline & Testler & $X$ & SS & $\mathrm{Z}$ & $\mathbf{P}$ & $\mathrm{X}$ & SS & & \\
\hline \multirow[b]{2}{*}{ Pas Atışı } & Ön Test & 3,59 & 0,51 & \multirow[b]{2}{*}{$-3,787$} & \multirow[b]{2}{*}{$\mathrm{p}=, 000^{*}$} & 1,93 & 0,8 & \multirow[b]{2}{*}{$\begin{array}{l}- \\
3,051\end{array}$} & \multirow[b]{2}{*}{$\mathrm{p}=, 002^{*}$} \\
\hline & $\begin{array}{l}\text { Son } \\
\text { Test }\end{array}$ & 4,88 & 0,33 & & & 2,67 & 0,9 & & \\
\hline \multirow{2}{*}{ Şut Atışı } & Ön Test & 4,88 & 0,33 & \multirow[b]{2}{*}{$-3,256$} & \multirow[b]{2}{*}{$\mathrm{p}=, 001^{*}$} & 1,67 & 0,82 & \multirow[b]{2}{*}{,- 816} & \multirow[b]{2}{*}{$\mathrm{p}=, 414$} \\
\hline & $\begin{array}{l}\text { Son } \\
\text { Test }\end{array}$ & 3,59 & 0,94 & & & 1,53 & 0,64 & & \\
\hline \multirow[b]{2}{*}{ Penaltı Atışı } & Ön Test & 1,94 & 1,03 & \multirow[b]{2}{*}{$-3,443$} & \multirow[b]{2}{*}{$\mathrm{p}=, 001^{*}$} & 1,60 & 0,63 & \multirow{2}{*}{$\begin{array}{l}- \\
2,449\end{array}$} & \multirow[b]{2}{*}{$\mathrm{p}=, 014^{*}$} \\
\hline & $\begin{array}{l}\text { Son } \\
\text { Test }\end{array}$ & 4,18 & 0,73 & & & 2,00 & 0,76 & & \\
\hline \multirow{2}{*}{$\begin{array}{l}\text { Turnike } \\
\text { Atışı }\end{array}$} & Ön Test & 1,82 & 0,73 & \multirow[b]{2}{*}{$-3,559$} & \multirow[b]{2}{*}{$\mathrm{p}=, 000^{*}$} & 1,60 & 0,91 & \multirow[b]{2}{*}{,- 577} & \multirow[b]{2}{*}{$\mathrm{p}=, 564$} \\
\hline & $\begin{array}{l}\text { Son } \\
\text { Test }\end{array}$ & 4,00 & 0,79 & & & 1,67 & 0,98 & & \\
\hline \multirow[b]{2}{*}{$\begin{array}{l}\text { V-Kat } \\
\text { Atışı }\end{array}$} & Ön Test & 1,24 & 0,56 & \multirow[b]{2}{*}{$-3,575$} & \multirow[b]{2}{*}{$\mathrm{p}=, 001^{*}$} & 1,60 & 0,74 & \multirow[b]{2}{*}{$\begin{array}{l}- \\
2,236\end{array}$} & \multirow[b]{2}{*}{$\mathrm{p}=, 025^{*}$} \\
\hline & $\begin{array}{l}\text { Son } \\
\text { Test }\end{array}$ & 3,00 & 1,00 & & & 1,27 & 0,46 & & \\
\hline
\end{tabular}

$*=0<0.05$.

Tablo 4. Deney ve Kontrol Grubunun Gruplar Arası Son Test Ölçüm Değerlerinin Mann Whitney U Testi Sonuçlarn

\begin{tabular}{|c|c|c|c|c|c|c|}
\hline Değişkenler & Gruplar & $\mathrm{N}=32$ & $X$ & SS & $\mathrm{Z}$ & $\mathbf{P}$ \\
\hline \multirow{2}{*}{ Pas Atışı Son Test } & Deney Grubu & 17 & 4,88 & 0,33 & \multirow{2}{*}{$-5,054$} & \multirow{2}{*}{$\mathrm{p}=, 000$} \\
\hline & Kontrol Grubu & 15 & 2,67 & 0,9 & & \\
\hline \multirow{2}{*}{ Şut Atışı Son Test } & Deney Grubu & 17 & 3,59 & 0,94 & \multirow{2}{*}{$-4,631$} & \multirow{2}{*}{$\mathrm{p}=, 000$} \\
\hline & Kontrol Grubu & 15 & 1,53 & 0,64 & & \\
\hline \multirow{2}{*}{ Penaltı Atış1 Son Test } & Deney Grubu & 17 & 4,18 & 0,73 & \multirow{2}{*}{$-4,693$} & \multirow{2}{*}{$\mathrm{p}=, 000$} \\
\hline & Kontrol Grubu & 15 & 2,00 & 0,76 & & \\
\hline \multirow{2}{*}{$\begin{array}{l}\text { Turnike Atışı Son } \\
\text { Test }\end{array}$} & Deney Grubu & 17 & 4,00 & 0,79 & \multirow{2}{*}{$-4,422$} & \multirow{2}{*}{$\mathrm{p}=, 000$} \\
\hline & Kontrol Grubu & 15 & 1,67 & 0,98 & & \\
\hline \multirow{2}{*}{$\begin{array}{l}\text { V-Kat Şut Atışı Son } \\
\text { Test }\end{array}$} & Deney Grubu & 17 & 3,00 & 1,00 & \multirow{2}{*}{$-4,484$} & \multirow{2}{*}{$\mathrm{p}=, 000$} \\
\hline & Kontrol Grubu & 15 & 1,27 & 0,46 & & \\
\hline
\end{tabular}

${ }^{*}=p<0.05$.

Tablo 4'de görüldüğü üzere deney grubu ile kontrol grubunun pas, şut, penaltı, turnike ve V-kat şut atışlarının son ölçüm değerleri arasında istatistiksel olarak ileri düzeyde önemli farklılıklar bulunmuştur $(p=, 000)$. 


\section{Tartışma ve Sonuç}

Yapılan literatür taramasında gelişim dönemindeki çocukların korfbol branşının temel motor becerilerine yönelik fazla bir çalışmaya rastlanmamıştır. Korfbol oyunun basketbol branşı ile olan benzerliğinden (Bottenburg ve Vermeulen, 2014) yola çkarak, bu branşa yönelik yapılan bu çalışmadaki sonuçlar ayrıca basketbol branşına yönelik literatür çerçevesinde de karşılaştırılarak tartışılmıştır.

Çalışmada elde edilen sonuçlara bakıldığında; deney grubunun ön-son test ölçüm değerleri arasında pas, şut, penaltı, turnike ve V-kat şut atışı değişkenlerinde, kontrol grubunun ön-son test ölçüm değerleri arasında ise pas, penaltı ve V-kat şut atışı değişkenlerinde önemli düzeyde fark olduğu saptanmıştır $(\mathrm{p}<0.05)$. Deney grubu ile kontrol grubunun karşılaştırılmasında; pas, şut, penaltı, turnike ve V-kat şut atışlarının son ölçüm değerleri arasında ileri düzeyde önemli fark olduğu ortaya çıkmıştır ( $\mathrm{p}<0.05)$.

Godinho ve arkadaşları (1996), Hollandalı 39 korfbol oyuncusunun morfolojik ve antropometrik karakterizasyonlarını incelediği çalışmada, korfbolcuların basketbol ve voleybol oyuncularından daha küçük ve daha düşük ağırlığa sahip olduğunu ve bunun yanısıra diğer takım sporcularından ise daha ağır ve daha uzun olduklarını saptamışlardır.

Ram ve Kumar (2015) üniversitelerarası ligde oynayan 45 korfbol oyuncusunun performansları ile birlikte antropometrik ölçüm ve fiziksel uygunlukları arasındaki ilişkiyi incelemeyi amaçladıkları çalışmada, korfbol oyuncularının performansıyla antropometrik ölçüm değerleri ve fitness düzeyi arasında pozitif bir ilişki olduğu belirtilmiştir.

Literatürde bu çalışmadaki araştırma grubundan farklı branşlara ve yaş aralıklarına sahip sporculara yönelik olarak motor davranış becerilerinin gözlem yoluyla test edildiği çalışmalara rastlanmaktadır.

Bayazıt ve arkadaşları (2007), 11-14 yaş aralığındaki eğitilebilir zihinsel engelli çocuklarda kaynaştırma eğitimi yöntemi ile 8 hafta süresince uygulanan eğlenceli atletizm antrenman programının motor özelliklere etkisini "Eğlenceli Atletizm Beceri Testi" ve "Motor Davranış Değişikliğine Yönelik Gözlem Formu" kullanarak inceledikleri çalışmada, antrenman sonrasında hem partnerli hem partnersiz gruplarda istatistiksel anlamda gelişme oldu- 
ğunu, buna karşın kontrol grubunda ise herhangi bir gelişme olmadığını rapor etmişlerdir. Ayrıca eşli olarak çalışan kaynaştırma grubunun motor beceri davranış değişikliğinde önemli bir artış gözlemlendiğini belirtmişler$\operatorname{dir}(\mathrm{p}<0.05)$.

Pense ve Serpek (2010)'in basketbol oynayan 14-16 yaş grubu adolesan dönemi kız öğrencilerine yönelik yaptıkları çalışmada, denek grubunun belirlenmiş fizyolojik ve biyomotor değerlerinin kontrol gruplarına göre pozitif yönde gelişme gösterdiği rapor edilmiştir. Kız basketbolcuların, boy uzunluklarının, mekik sayılarının, dengede kalış sürelerinin, esneklik, durarak uzun atlama mesafelerinin, pençe kuvvetlerinin vs. kontrol grubuna kıyasla daha hızlı olduğu ve ortaya çıkan bu farkın istatistiksel olarak önemli düzeyde olduğu bildirilmiştir $(\mathrm{p}<0.05)$.

Gül ve arkadaşlarının (2006) yapmış olduğu çalışmada, temel atletizm eğitimini düzenli alan çocuklarda hareket becerilerini öğrenmede önemli bir gelişme olduğu belirtilmiştir.

Özçelik ve Alpullu (2019) çalışmasında, 16-18 yaş aralığındaki 24 erkek basketbolcunun 8 hafta süresince antrenman programlarına eklenmiş farklılikla öğrenme yönteminin, basketbolun temel teknik hareketleri (pas verme, şut atma, top sürme ve turnike atışı) üzerindeki etkisini ve gelişimlerini incelenmiş, uygulanan farklılık yöntemlerinin basketbol becerileri üzerinde anlamlı gelişmeler sağladığı belirtilmiştir $(\mathrm{p}<0.05)$. Yapılan bu çalışma, uygulanan antrenman programının içeriği bakımından alan yazını destekler niteliktedir.

Gültekin (2009), ilköğretim 5. ve 6. sinıfta öğrenim gören 119 öğrencinin beden eğitimi derslerinde kullanılan görsel materyallerle öğretim yönteminin, basketbol branşının temel becerilerinin öğretiminde psikomotor öğrenmeye etkisini basketbol temel beceri gözlem formu kullanarak test etmişlerdir. Çalışma sonucunda araştırmacılar tarafından görsel materyaller ile yapılan basketbol eğitiminin deney grubu lehine olumlu yönde katkılar sağladığı vurgulanmıştır.

Santos ve arkadaşlarının (2017) üniversite öğrencileri üzerinde yaptığ1 çalışmada, basketbolda teknik-taktik becerilerin ve motor özelliklerin bireylere kazandırılması noktasında özellikle erken yaşlarda spor deneyimlerinin kazanılmasının büyük öneme sahip olduğu ifade edilmektedir.

Gökmen ve arkadaşlarının (1995) yaptı̆̆ çalışmada, özellikle 9-11 yaş dönemindeki çocukların bedensel yapılarındaki değişimin bilinmesi, çocu- 
ğun bedenini daha iyi tanıması ve onu daha verimli kullanmaya çalışması açısından gayret göstermesinin sportif hareketleri geliştirmesinde önemli bir aşama olduğu vurgulamaktadır.

Koordinasyon, çeviklik ve denge içerikli hareket eğitimi uygulamalarının tüm spor branşlarındaki sportif tekniklerin öğretilmesi aşamasında, branşa özgü hareket becerilerinin kazandırılmasında ve geliştirilmesinde önemli bir etkiye sahip olduğu ifade edilmektedir (Önal, 2016).

Bununla birlikte çok yönlü hareket eğitimi içeren çalışmaların (koşu, atma, atlama, sıçrama vb.) farklı şekillendirilmiş oyunlar içerisinde düzenli bir biçimde tekrar edilerek uygulanması, çocukların psikomotor gelişimine ciddi katkılar sağlamaktadır (Haslofça, 2017).

Bu çalışma sonucunda, 8 hafta boyunca düzenli olarak uygulanan korfbol temel beceri eğitimi antrenman programının çocukların korfbol temel motor becerilerini öğrenmesi ve uygulaması üzerinde olumlu yönde etkisi olduğu söylenebilir.

\section{Öneriler}

Türkiye'de son birkaç yıldır bazı bölgelerde tanınmaya ve lig düzeyinde müsabakalar düzenlenmeye başlanan bu sporun popülaritesini arttırmak amacryla bu branşa özgü psikososyal, fizyolojik ve yönetimsel alanda daha fazla bilimsel çalışmaların yapılması bu branşın tanıtılmasının yanısıra hem yaş kategorilerinin genişletilmesine hem de bölgesel olarak yaygınlaştırılmasına katkı sağlayacaktır. Dolayısıyla bu çalışmanın, hem korfbol sporundaki motor becerilerin öğrenilmesine hem de sportif yeteneğin ve performansın geliştirilmesine yönelik yapılacak yeni çalışmalara ışık tutacağı düşünülmektedir. 


\title{
EXTENDED ABSTRACT
}

\section{The Effect of Korfball Basic Skill Education Training Program on Motor Development in Children of 14 -16 Years \\ *}

\author{
Canan Gülbin Eskiyecek - Betül Bayazıt - Dilruba Abdikoğlu \\ Mardin Artuklu University, Kocaeli University
}

Movement is explained as the observable change of position of any part of the body as well as the top action of the basic motor processes (Gallahue, 2014). The period when the movement skills and techniques can be gained the fastest is the childhood period in which the development is the fastest. Sports contributes to children's physical, motor, mental and emotional development (Sema, 2007; Polat, 2009). Therefore, it is predicted that the sports activities performed in childhood due to the known benefit of sports on children's development will positively affect the quality of life of children.

The players of the korfball branch, which is one of the sports branches represented by talented athletes in international competitions in our country, has less body fat, more lean body mass, more limb fat, and less or similar body fat compared to other athletes (Godinho et al., 1996). The main catalyst in the development of Korfball sports is that boys and girls can participate in a level playing field and a cooperative and mixed sport is needed (Summerfield and White, 1989).

In the literature review, it is seen that there is not much study on basic motor skills of the korfball branch of children in the development period and the related studies are limited. Therefore, it is thought that researches are needed to develop basic technical skills, motoric features and coordinative skills specific to this branch.

Starting form this; the last few years in Turkey, which is being recognized in competitions and league level in some areas to increase the popularity of this sport; more scientific studies in the psychosocial, physiological and managerial fields specific to this branch will contribute to the widening of the age categories as well as the regional expansion of this branch. 
In this context, this study was carried out to determine the effects of basic skill training for the korfball branch on the motor development of boys and girls aged 14-16.

Regardless of gender in the study, students were divided into two groups, 17 ( 5 girls- 12 boys) subjects and 15 (7 girls- 8 boys) of the control group by random method. "Informed Volunteer Consent Form" signed by all students and parents was taken in the study. Ethics Committee Approval was received from Kocaeli University Non-Interventional Clinical Research Ethics Committee with the number "KOGOEK 2019 / 01.2" and "KÜ GOKAEK 2018/346" to conduct the study. In the study, "Observation Form for Motor Behavior Change" (pass, shot, penalty, tourniquet, and V floor shot) was used to determine the effect of the korfball basic skill training of children in the experimental and control groups on motor development, and this form was applied to students before and after the training program. A training program that includes locomotor, balancing and manipulative movements were applied to the experimental group for 2 days in a week for 8 weeks, and 60 minutes per day to improve the basic movement skills of korfball. The loading intensity of the training program was increased by $5 \%$ every two weeks. No training program was applied to the control group. In the study that lasted for 8 weeks, the pretest and posttest measurements were compared on the observation form and the results were evaluated. Also, children's height, body weights, sitting heights, and diameter-perimeter measurements were taken in the tests. All groups were given dynamic warm-up for 15 minutes before the test, and then the children were put into practice at the stations prepared for skill tests.

With the data obtained in the study, SPSS 24.0 statistical package program was used to analyze descriptive statistics. Mann Whitney U test was used to determine the difference between the groups and the Wilcoxon test was used to determine the difference within the groups. In the evaluation of the results, the significance level was accepted as $\alpha=0.05$.

Considering the results obtained in the study; there was a significant difference between the pretest and posttest measurement values of the experimental group in the pass, shot, penalty, tourniquet and V-floor shot variables, and between the control group's pre and post test measurements there was a significant difference in the pass, penalty and V-floor shot-throw variables $(\mathrm{p}<0.05)$. In the comparison of the experimental group and the control 
group; it was revealed that there was a significant difference between the last measurement values of the pass, shot, penalty, tourniquet and V-floor shot $(\mathrm{p}<0.05)$.

As a result of this study, it can be said that the korfball basic skill training program, which is applied regularly for 8 weeks, has a positive effect on children's learning and application of korfball basic motor skills.

Starting form this; the last few years in Turkey, which is being recognized in competitions and league level in some areas to increase the popularity of this sport; more scientific studies in the psychosocial, physiological and managerial fields specific to this branch will contribute to the widening of the age categories as well as the regional expansion of this branch

\section{Kaynakça / References}

Bayazıt, B., Meriç, B., Aydın, M. ve Seyrek, E. (2007). Eğitilebilir zihinsel engelli çocuklarda eğlenceli atletizm antrenman programının psikomotor özelliklere etkisi. Spormetre Beden Eğitimi ve Spor Bilimleri Dergisi, 4, 173-176.

Biçici, R., Ayhan, S. ve Kavak, V. (2009). The motoric properties of individual and team sportsman. Ovidius University Annals, Series Physical Education And Sport / Science, Movement And Health, 9(2), 103-111.

Bottenburg, M. V. ve Vermeulen, J. (2011). Local korfball versus global basketball: A study of the relationship between sports' rule-making and dissemination. Dans Ethnologie française, 4(41), 633- 643.

Gallahue, D. L., Ozmun, J. C. ve Goodway, J. D. (2014). Motor gelişimi anlamak. bebekler, çocuklar, ergenler, yetişkinler (çev.Ed. D. S. Özer, ve A. Aktop). Ankara: Nobel Akademik Yayıncilık.

Godinho, M., Fragoso, I. ve Vieira, F. (1996). Morphologic and anthropometric characteristics of high level Dutch korfball players. Percept Mot Skills, 82(1), 35-42. doi:10.2466/pms.1996.82.1.35

Gökmen, H., Karagül, T. ve Aşçı, F. H. (1995). Psikomotor gelişim. GSGM, Yayın No:139, Ankara.

Gül, G. K., Seyrek, E. ve Sugurtin, M. (2006). 10-12 yaş temel atletizm spor eğitimi alan ve almayan erkek çocuklar arasındaki bazı antropometrik ve motorik özelliklerin karşılaştırılması. 9. Uluslararası Spor Bilimleri Kongresi, Muğla.

Güler, L. (1998). Türkiye'de yeni bir spor dalı: "Korfbol". Beden Eğitimi ve Araştırmaları, 20-22. 
Gültekin, B. (2009). Illköğretim 5. ve 6. sinıf beden eğitimi derslerindeki bazı basketbol temel becerilerinin öğretiminde görsel materyallerin psikomotor öğrenmeye etkisinin incelenmesi. Yüksek Lisans Tezi, Marmara Üniversitesi, Eğitim Bilimleri Enstitüsü, Spor Eğitimi Anabilim Dall, İstanbul.

Günsel, A. N. (2004). İlköğretimde beden eğitimi ve uygulamaları. Anı Yayınları, Ankara, 24-30-31.

Haslofça, F. (2017). Ortaokullar için atletizm. ders içi ve ders dişı etkinliklerde ıaaf çocuk atletizm oyunlar ile atletizm eğitimi. Spor Yayınevi ve Kitabevi, Ankara, Türkiye.

Korfball (2020, February 19) Korfball history. 03 Mart 2020 tarihinde https://en.wikipedia.org/wiki/Korfball adresinden erişildi

Oxendine, B. (1982). Psychology of motor learning II. (1.Edt), New York: Mayfield Publications. 270-295, 315-317.

Önal, A., Yaman, N., Berisha, M., Hergüner, G. ve Yaman, Ç. (2016). Examining the effect of psychomotor training on the coordination, agility and balance in 10-11 year-old girls. International Refereed Academic Journal of Sports, Health and Medical Sciences, 21, 137-148.

Özçelik, M. ve Alpullu, A. (2019). Farklılıkla öğrenme antrenmanlarının basketbol oyuncuları üzerindeki etkisi. Eurasian Research in Sport Science, 4(1), 34-52. doi:10.22396/ERISS.2019153191

Pense, M. ve Serpek, B. (2010). 14-16 Yaş Arası Basketbol Oynayan Kız Öğrencilerin Fizyolojik ve Biyomotorik Özelliklerinin Eurofit Test Bataryası ile Belirlenmesi. Selçuk Üniversitesi Beden Eğitimi ve Spor Bilim Dergisi, 12(3), 191-198.

Polat, G. (2009). 9-12 yaş grubu çocuklarda 12 haftalık temel badminton eğitimi antrenmanlarının motorik fonksiyonları ve reaksiyon zamanları üzerine etkileri. Yüksek Lisans Tezi, Çukurova Üniversitesi Sağlık Bilimleri Enstitüsü Beden Eğitimi ve Anabilim Dalı, Adana.

Ram, M. ve Kumar M. (2015). Relationship of anthropometric measurement and physical fitness with performance of intercollegiate Korfball players. International Journal of Applied Research, 1(11), 259-264.

Santos, S., Mateus, N., Sampaio, J. ve Leite, N. (2017). Do previous sports experiences influence the effect of an enrichment programme in basketball skills? Journal of Sports Science, 35(17), 1759-1767. doi:10.1 080/02640.414.2016.1236206 
Sema, C. (2017). 10 -12 yaş grubundaki erkek tenisçiler masa tenisçiler aynı yaş grubu sedanterlerin reaksiyon zamanlarının karşılaştırılması. Yüksek Lisans Tezi, Gazi Üniversitesi, Sağlık Bilimleri Enstitüsü Beden Eğitimi ve Spor Anabilim Dall, Ankara.

Summerfield, K. ve White, A. (1989). Korfball: A model of egalitarianism. Sociology of Sport Journal, 6, 144-151.

\section{Kaynakça Bilgisi / Citation Information}

Eskiyecek, C. G., Bayazıt, B. ve Abdikoğlu, D. (2020). 14 -16 yaş grubu çocuklarda korfbol temel beceri eğitimi antrenman programının motor gelişime etkisi. OPUS-Uluslararası Toplum Araştırmaları Dergisi , 15(23), 1976-1992. DOI: 10.26466-/opus.672410 